\title{
Analysis of the mechanical and fracture behavior of heated ultra-high-performance fiber-reinforced concrete by X-ray computed tomography
}

\author{
José D. Ríos ${ }^{\mathrm{a}}$, Héctor Cifuentes $^{\mathrm{a}, *}$, Carlos Leiva $^{\mathrm{b}}$, Stanislav Seitl $^{\mathrm{c}}$ \\ ${ }^{a}$ School of Engineering, Department of Continuum Mechanics and Structural Analysis. University of \\ Seville, Camino de los Descubrimientos, s/n, 41092, Seville, Spain \\ ${ }^{b}$ School of Engineering, Department of Chemical and Environmental Engineering. University of Seville, \\ Camino de los Descubrimientos, s/n, 41092, Seville, Spain \\ ${ }^{c}$ Academy of Sciences of the Czech Republic, Institute of Physics of Materials, ÅxiÄŸkova 22, 61662 Brno, \\ Czech Republic
}

\begin{abstract}
This work analyzes the effects of temperature $\left(300{ }^{\circ} \mathrm{C}\right)$ on mechanical and fracture behavior of an ultra-high-performance steel-fiber-reinforced concrete. The deterioration of the pore structure due to thermal damage of the fiber-reinforced concrete and its un-reinforced matrix was analyzed by X-ray computed tomography. Complementary, a thermogravimetric analysis was performed to relate the observed phase changes, due to dehydration and decomposition, with the deterioration of pore structure. Additionally, an analysis of their mechanical and fracture properties was also done at room temperature and $300^{\circ} \mathrm{C}$. Finally, it was established a connection between the damage within the concrete matrix and its corresponding mechanical behavior. From results, it has been ascertained that the propagation of thermal damage within the matrix affects in different ways depending on the pore-size. The presence of fibers modifies the pore structure and consequently the evolution of the thermal damage in the ultra-highperformance concrete, inferring into its mechanical and fracture behavior.

Keywords: ultra-high performance concrete, X-ray computed tomography, steel fibers, high temperature, thermal effects, fracture
\end{abstract}

\footnotetext{
${ }^{*}$ Corresponding author

Email address: bulte@us.es (Héctor Cifuentes)
} 


\section{Introduction}

Ultra-high-performance fiber-reinforced concrete (UHPFRC) is characterized by a water-to-binder ratio usually below 0.2 and by being made from constituents with very fine particle size to fill the matrix tiny holes and enhance the hydration process [1, 2].

5 This leads to a high matrix packing density that provides exceptional durability and high brittleness [3, 4]. The reinforcement of this type of concrete, commonly with steel fibers in quantities of more than $2 \%$ by volume, infers a significant improvement on its mechanical properties, especially on the tensile and flexural strength, as well as an excellent energy absorption capacity and ductility [5, 6]. Nevertheless, several studies reveal that the addition of fibers can alter the distribution of the pore structure [7, 8], as well as increase the porosity in the matrix [9, 10]. Furthermore, the pore morphology is an important factor on thermal conductivity of concrete [11, 12] and as a consequence, on generation of the thermal gradients in the concrete matrix at temperature exposure. The internal stresses generated by the thermal gradients combined with the pore pressure from the water evaporation can reach the tensile strength of concrete and produce explosive spalling [11, 13, 14, 15].

The spalling effects produce more severe deterioration in the UHPFRC than those of normal concrete (NC) or high-strength concrete (HSC) due to its lower porosity which does not allow that the evaporated water can flow outside through the pore connection of the matrix [15, 16, 17]. Although there are numerous research paper focused on the mechanical behavior [18, 19, 20, 21, 22] and fracture properties of UHPFRC $[23,24,25,26,27]$, there are no many studies that relate the mechanical or fracture properties of UHPFRC with the matrix pore structure [20, 28].

On the other hand, most of research related with the influence of temperature on the behavior of UHPFRC have been focused on fire resistance [29, 30, 31] due to this type of concrete is widely applied in civil structures. As UHPFRC contains a high amount of cement, the shrinkage cracking is similarly of research interest into this type of concrete [6, 32, 33, 34]. Several studies have been focused on curing or recuring processes since the temperature exposure during the curing stage or its useful life modify the strength evolution [11, 19, 35]. However, in some applications the 
UHPFRC must be capable of bearing thermal and mechanical loads simultaneously for long periods of time, like in structures for molten salt or water vapor storage tanks in solar power plants, as well as in energy storage systems by solid medium, in which, the concrete material directly stores the thermal energy. In this regard, to know the evolution of the mechanical and fracture behavior of UHPFRC at moderate temperature exposure for long periods of time is worthy of study. This kind of study, relating the mechanical and fracture properties with the porosity evolution inside the UHPFRC at room and moderately elevated temperature, are really scarce the literature.

This work is focused on the influence of temperature exposure for significant periods on the pore structure deterioration and the consequences on the mechanical and fracture properties of an UHPFRC. To this, a comprehensive experimental campaign to determine the mechanical and fracture properties of a UHPFRC and its corresponding non-reinforced matrix at room temperature and $300{ }^{\circ} \mathrm{C}$ was performed. The influence of porous morphology on the mechanical and fracture behavior at each temperature was measured through X-ray computed tomography (CT) scan. A post-processing of the X-ray CT images allowed for us to obtain a three-dimensional reconstruction of samples in order to identify the pore distribution in the concrete matrix and to obtain the main porosity parameters for a wide range of pore sizes. These were determined for fiber-reinforced concrete (UHPFRC) and its corresponding matrix without any reinforcement (UHPC) at room temperature and for exactly the same samples heated to $300^{\circ} \mathrm{C}$. Additionally, a thermogravimetric analyses of the concrete matrix (UHPC) was conducted from room temperature to $400{ }^{\circ} \mathrm{C}$ in order to determine the phase changes due to dehydration or decomposition at each temperature [16, 36] and an X-ray crystallography analysis to determine the mineral composition of UHPC. Finally, it was established a connection among the results from thermoanalytic techniques, X-ray CT scan and the mechanical and fracture properties at room temperature and $300{ }^{\circ} \mathrm{C}$. In this way, the mechanisms by which the changes in microstructure of the matrix, originated by the presence of fibers and the increase of the temperature, determine the mechanical and fracture properties of concrete has been thoroughly analyzed.

This paper is structured in the following manner: A description of experimental procedure and thermal analyses techniques are presented in Section 2, the results of the 
tests are exposed and discussed in Section 3 and finally the conclusions are found in Section 4.

\section{Experimental procedure}

In this section, a summary of the materials, TG analyses, X-ray CT scan and experimental tests performed are shown.

\subsection{Materials and mix design}

In this work, two different ultra-high-performance concrete mixes were manufactured. The former was a non fiber-reinforced concrete (UHPC) used as control mix and the latter was a fiber-reinforced concrete (UHPFRC). The concrete matrix was exactly the same for both mixes and following the proportions shown in Table 1 . The mix design was done in accordance with the recommendations postulated by Deeb et al. [37]. Three constituents comprise the binder materials: the type I cement of $52.5 \mathrm{R} / \mathrm{SR}$, the silica fume S-92-D from SIKA company and the ground granulated blast-furnace slag (ggbs) provided by Arcelor company. Two quartz sands were added as aggregate: the former with a maximum size of $315 \mu \mathrm{m}$ and the latter with $800 \mu \mathrm{m}$. The superplasticizer, used as reducer of water, was a third generation polycarboxylic ether-based type (Master-Glenium ACE 325) with a specific gravity of 1.05 provided by BASF Company. 
Table 1: Nomenclature and mix proportions

\begin{tabular}{c|c|c}
\hline Constituent & UHPC $\left(\mathrm{kg} / \mathrm{m}^{3}\right)$ & UHPFRC $\left(\mathrm{kg} / \mathrm{m}^{3}\right)$ \\
\hline cement & 544 & 544 \\
silica fume & 214 & 214 \\
ggbs & 312 & 312 \\
water & 188 & 188 \\
fine sand $(<315 \mu \mathrm{m})$ & 470 & 470 \\
coarse sand $(<800 \mu \mathrm{m})$ & 470 & 470 \\
superplasticizer (BASF ACE 325) & 42 & 42 \\
steel fiber OL 13/0.2 & - & 98 \\
steel fiber C80/30BP & - & 98 \\
\hline w/c ratio & 0.34 & 0.34 \\
w/binder ratio & 0.17 & 0.17 \\
\hline
\end{tabular}

In the UHPFRC, the reinforcement was exclusively using micro and macro steel fibers. The shortest smooth micro-fibers were the OL 13/0.2 model manufactured by the Bekaert company and with $13 \mathrm{~mm}$ in length, $0.20 \mathrm{~mm}$ in diameter and straight ends. The macrofibers were the C80/30BP model by the same company, measuring $30 \mathrm{~mm}$ in length, $0.38 \mathrm{~mm}$ in diameter and fitted with hooked ends. The UHPFRC mix has a fiber content of $2.5 \%$ by volume fraction which means $196 \mathrm{~kg} / \mathrm{m}^{3}$ in a $50 \%$ ratio of each type of fiber. The nomenclature of concrete and fiber proportions can be also seen in Table 1 The mineral composition of UHPC after 28 days obtained by X-ray diffraction technique is shown in Figure 1. The main mineral compounds at room temperature were fundamentally quartz, $\mathrm{C}_{3} \mathrm{~S}: \mathrm{Ca}_{3} \mathrm{SiO}_{5}$ and $\mathrm{Ca}_{2} \mathrm{FeAlO}_{5}$. The pozzolanic reaction between the large amount of active $\mathrm{SiO}_{2}$ (siica fume) in the highstrength admixture and $\mathrm{Ca}(\mathrm{OH})_{2}$ generated during the cement hydration, has formed a lot of C-S-H gel and reducing $\mathrm{Ca}(\mathrm{OH})_{2}$ and $\mathrm{CaCO}_{3}$ content, as it can be seen in Figure 1][16]. 


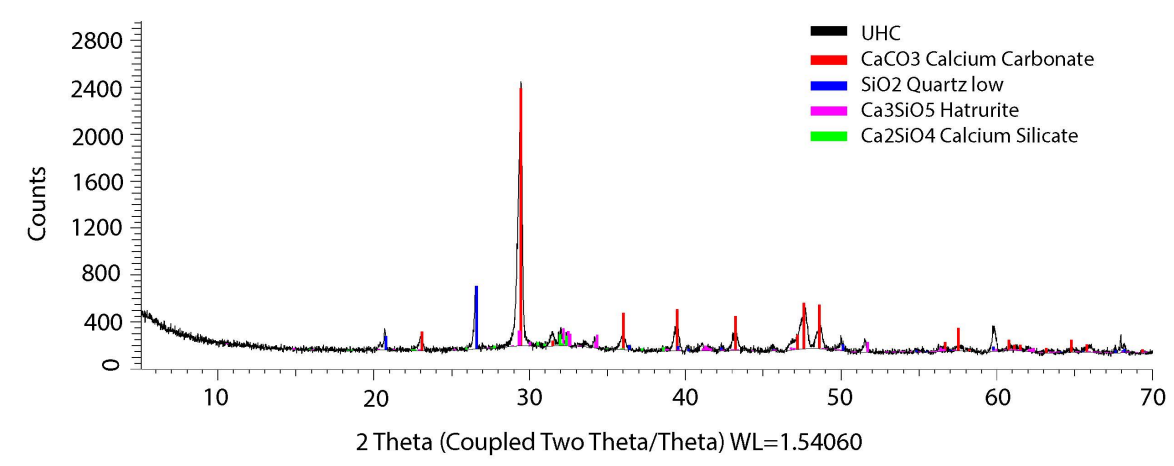

Figure 1: Mineral composition of UHPC

\subsection{Thermoanalytic tests}

Simultaneous thermogravimetric analyses (TA), differential thermal analyses (DTA) and differential scanning calorimetric (DSC) measurements were performed at the Functional Characterization Service (University of Seville, Spain) on a TA (model Q600-SDT) instrument, using alumina as reference material. The specimens were placed into crucibles in a chamber within ambient air during the entire heating period. to $400{ }^{\circ} \mathrm{C}$.

\subsection{Mechanical and fracture tests}

Cubic specimens with $100 \mathrm{~mm}$ in length, cylindrical with $100 \mathrm{~mm}$ in diameter and $200 \mathrm{~mm}$ in height and $440 \times 100 \times 100 \mathrm{~mm}^{3}$ prismatic specimens were casted for measuring standardized mechanical and fracture properties at room temperature and $300^{\circ} \mathrm{C}$.

\subsubsection{Testing at room temperature}

The compressive strength was measured on four cubic specimens in accordance with the EN 12390-3 standard [38]. The tests were performed in a servo-hydraulic testing machine equipped with a load capacity of $3000 \mathrm{kN}$. The Young's modulus was experimentally determined by four cylindrical specimens for every mixture according 
to the EN 12390-13 standard [39]. This test was performed by gradually loading, with the same servo-hydraulic machine used for compression, until a third of its failure load and measuring the relative strain by two linear variable differential transformer (LVDT) sensors, $25 \mathrm{~mm}$ in length, one in front of the other, surrounding the cylinder. Four notched prismatic specimens were subjected to three-point bending tests for the determination of the fracture energy in accordance with the RILEM work-of-fracture method [40] and with the corrections proposed by Guinea et al. [41, 42, 43]. An inverse analyses based on the non-linear hinge model [44, 45, 46, 47] in order to obtain the values of the bilinear tension softening diagram (Figure 2) was also performed. The bilinear softening diagram allows for the numerical simulation of concrete in real applications [48]. Every specimen was sawn with a notch to depth ratio of one sixth. The specimens were set up with a LVDT, $30 \mathrm{~mm}$ in length, mounted on a rigid frame to avoid torsional effects, for both UHPC and UHPFRC to measure the mid-span deflection and a clip gage to measure the crack mouth opening displacement (CMOD). The utilization of the high range LVDT transducer allows the recording of the complete load-displacement curve even for the fiber-reinforced mix.

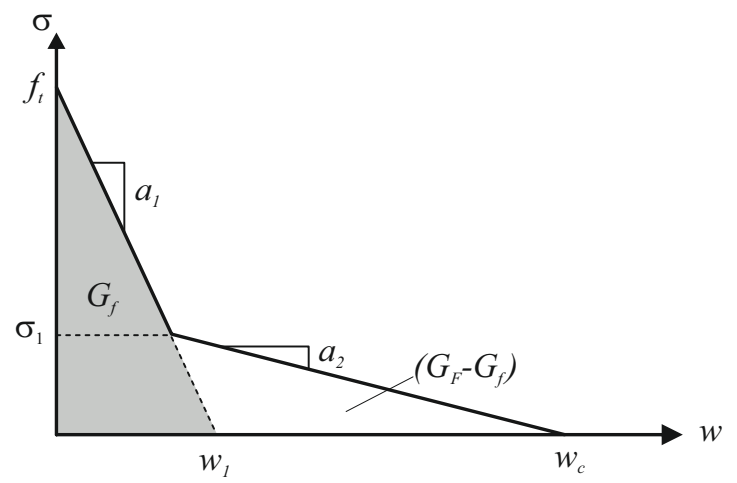

Figure 2: Bilinear tension softening diagram

\subsubsection{Testing at $300^{\circ} \mathrm{C}$}

The kind of tests and the number of specimens tested were the same as at room temperature. Nevertheless, some modifications had to be carried out owing to the temperature. The main drawback of high temperature tests is the impossibility of set the 
sensors on specimens. The three-point bending tests were done during entire testing within a furnace at $300^{\circ} \mathrm{C}$. In this way, the tests were performed on hot specimens with the fracture energy reaching lower values than in case of residual cooled specimens [49]. All specimens were heating for at least 24 hours before testing to ensure an homogeneous temperature in the material. The testing equipment of the aforementioned servo-hydraulic machine was specifically designed to be settled in a furnace. Thus, the actuator and supporting framework can be entered inside the chamber. Notwithstanding the foregoing, only load and actuator position data can be reported due to the transducers cannot bear such high temperatures.

For the estimation of the load-deflection curves from three point bending tests at $300{ }^{\circ} \mathrm{C}$, this procedure was followed:

- It is assumed that the difference between the mid-span deflection and the actuator displacement is due to the machine appliance strain during the loading process.

- From the room temperature tests, it is established a mid-span to deflectionactuator displacement ratio, $\Omega$, for each load applied.

$$
\Omega=\frac{X_{i}^{d e f}}{X_{i}^{p o s}}
$$

where $X_{i}^{\text {pos }}$ and $X_{i}^{\text {def }}$ are the actuator displacement and the mid-span deflection at RT respectively.

- At $300{ }^{\circ} \mathrm{C}$ tests, it is estimated the mid-span deflection data from the $\Omega$ ratio for each load recorded as follows:

$$
X_{i_{300}}^{\prime \text { def }}=\Omega X_{i_{300}}^{\text {pos }}
$$

where the $X_{i_{300}}^{\text {pos }}$ and $X_{i_{300}}^{\text {ddef }}$ are the actuator position and the estimated mid-span deflection at $300^{\circ} \mathrm{C}$ respectively.

For the estimation of the stress-strain curves on the Young's modulus tests the same procedure was followed but using LVDT data where the mid-span deflection. 


\subsection{X-ray computed tomography and image analyses}

The micro X-ray computed tomography technique was used to measure the porosity by air entrapped during manufacturing and thermal damage generated as result of the temperature exposure within the concrete matrix when the specimens reach $300{ }^{\circ} \mathrm{C}$. The X-ray inspection equipment, model Y.Cougar SMT of the YXLON company, from the X-ray Characterization Service of the University of Seville, Spain was used. It consists of a multi-focus tube and wolframio target which allows the inspection in the range between $25-160 \mathrm{kV}$ and 0.01-1 mA intensity. The equipment let generate 2D and 3D images with a maximum geometric magnification of $2000 \times$. The post-processing of reconstruction and treatment of images were carried out using the VGStudio MAX 2.2.3 software of the X-ray Service of the University of Seville. The X-ray CT samples analyzed were sawn from the prismatic specimens similar to those of the three-point bending tests $\left(440 \times 100 \times 100 \mathrm{~mm}^{3}\right)$ to avoid boundary effects in fiber distribution and their dimensions were approximately $100 \times 25 \times 25 \mathrm{~mm}^{3}$. A schematic overview of the dimensions and the zone from where every sample was extracted is shown in Figure 3 a. Eight samples, four of each mix (UHPC and UHPFRC) were analyzed, each sample was extracted from a different prismatic specimen. The same four samples were scanned at RT and after being subjected at $300{ }^{\circ} \mathrm{C}$.

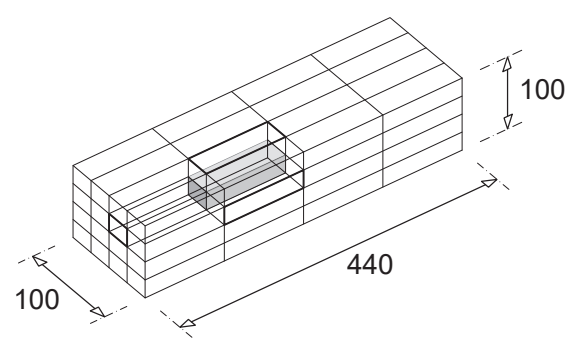

(a)

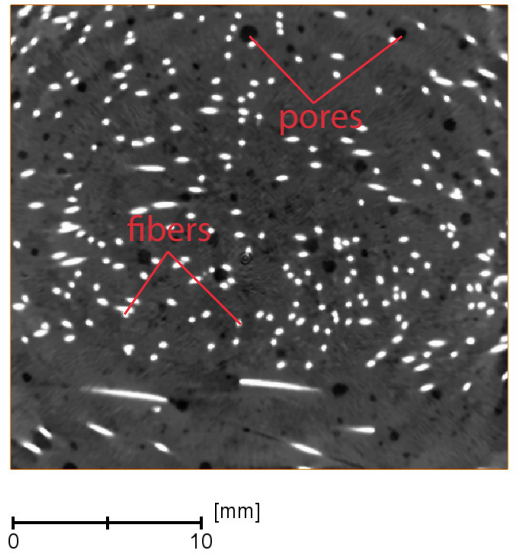

(b)

Figure 3: (a) Extraction of the sawn core from prismatic specimens (b) pores and fibers in grey-scale image 
The X-ray CT analyses scans multiple 2D X-ray radiographs (Figure $3 \mathrm{~b}$ ), in this case of 1024x1024 pixels, which finally are digitally reconstructed (Figure 4) into 3D absorption contrast image of the sample providing 3D information about the different density areas in the concrete matrix. The results, for these specific samples and materials, provided a resolution around $40 \mu \mathrm{m}$ in the three cartesian directions. The reduction of the artificial defects such as beam hardening and ring effects [50, 51] was done by post-processing. One of the multiple 2D images is shown in Figure 3 b, in which can 180 be observed: the darkest area, display the least density area (voids); the whitest area, the most density part (steel fibers) and the concrete matrix in the intermediate grey-tone values. 


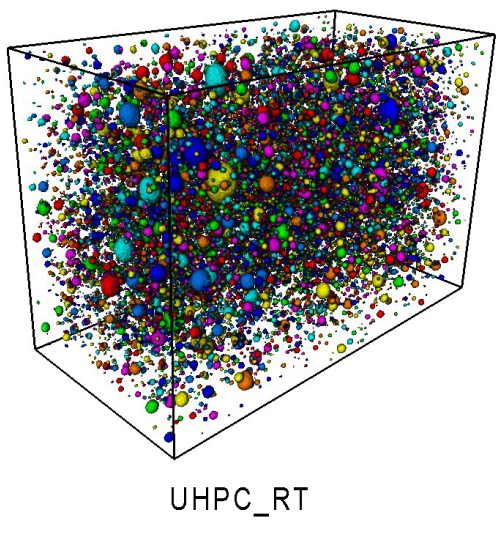

(a)

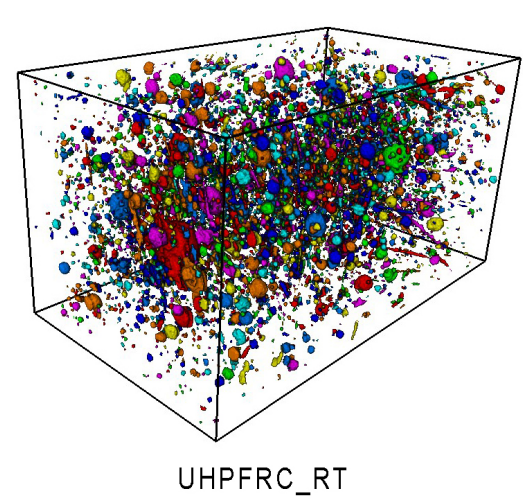

(c)

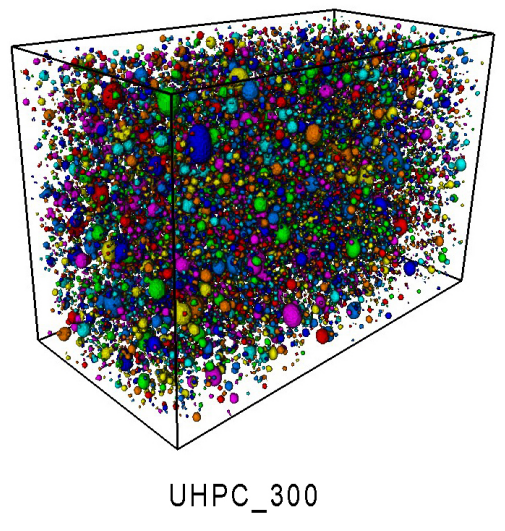

(b)

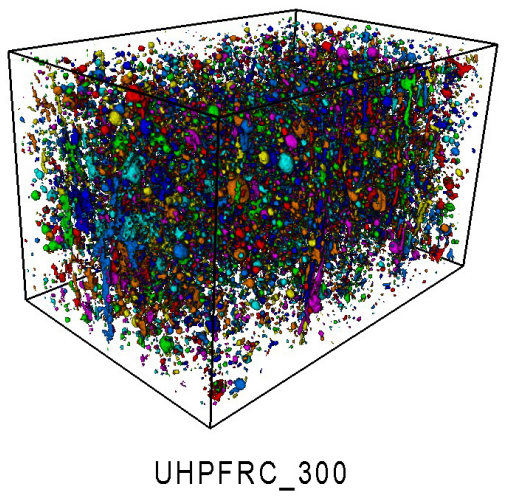

(d)

Figure 4: Pore distribution in specimens after 3D reconstruction (a) UHPC at RT (b) UHPC at $300{ }^{\circ} \mathrm{C}$ (c) UHPFRC at RT (d) UHPFRC at $300{ }^{\circ} \mathrm{C}$

The definition of the accurate grey-scale threshold which determines the interesting areas (matrix, pores and steel fibers) is essential for obtaining accurate and reliable data for analyzing [50]. For the segmentation into different phases according to grey-scale thresholds and post-processing analyses was used the AVIZO software. Figure 5 shows the sensitivity curves, proposed by Qsymah et al. [50], for the determination of the pore volume fraction according to grey-scale threshold values. 


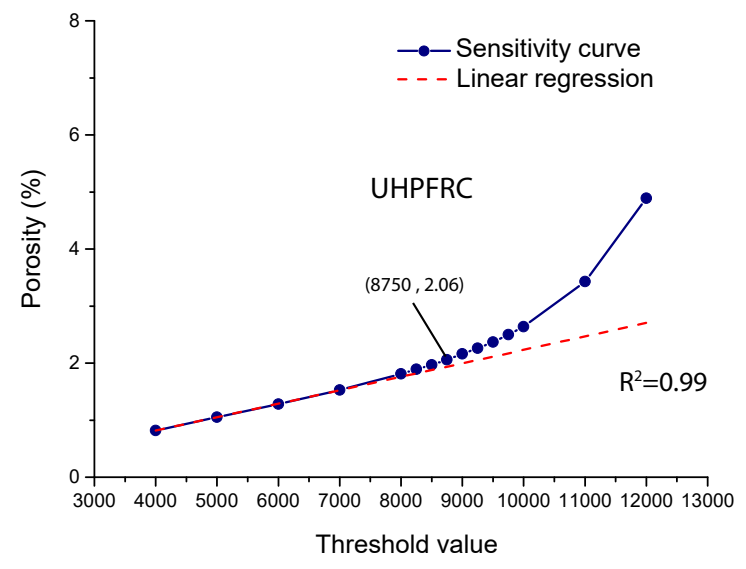

Figure 5: Sensitivity curve of pore volume fraction versus grey-scale threshold

The form of the sensitivity curves corresponds to an approximated linear progression within the lowest grey-scale threshold values. As can be seen in Figure 6, a, only part of the pores is selected (red zone) when grey-scale threshold values are low. Whether the threshold value is increased, the selected pore area (red zone) rises following an approximated linear progression [50]. Nonetheless, whether all of pores are closed to be completely selected, the darkest pixels within matrix area start to be filled and as a consequence, the linear progression becomes onto exponential form, as can be seen in Figure 5 In this study, the optimum threshold value has been chosen, for all samples analyzed, as the volume fraction value (circle points in Figure 5) that differs less than 0.1 from the linear regression line (dash line in Figure 5). That deviation was considered the most appropriate value which does not affect the solution. 

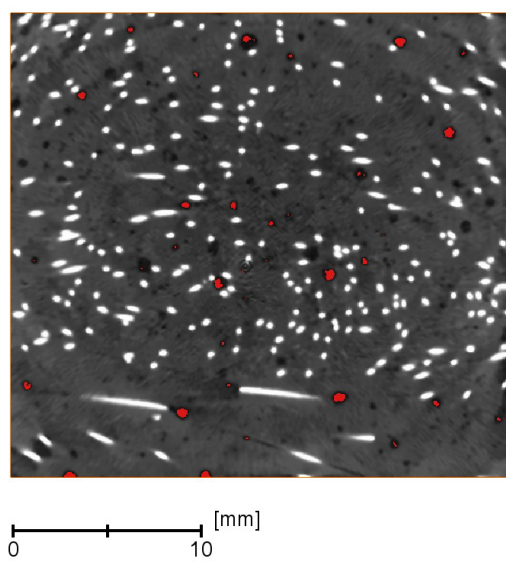

(a)

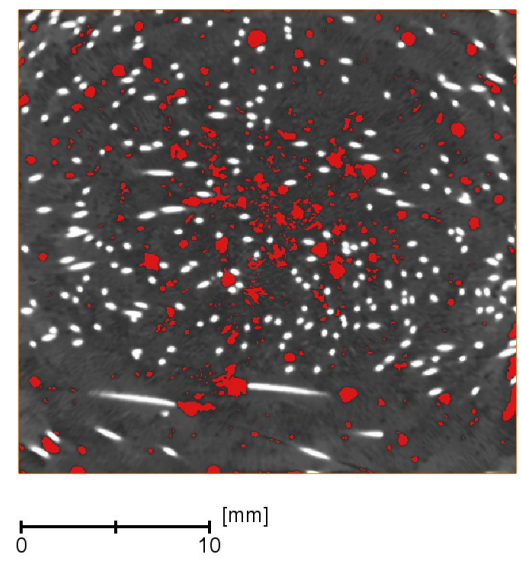

(b)

Figure 6: Pore segmentation areas for different grey-scale threshold values: a) 4000 b) 12000

\section{Results and discussion}

In this section, the results of the experimental tests for the determination of the phase changes by means of thermogravimetric curves, the X-Ray CT analyses of samples and the mechanical and fracture properties at room temperature and $300{ }^{\circ} \mathrm{C}$ are shown. The average value and the standard deviation are reported for each mixture.

\subsection{Thermal analyses}

The thermal equipment used to analyze the UHPFRC sample provides the thermogravimetric analyses (TG), the differential scanning calorimetry (DSC) and the differential thermal analyses (DTA) curves simultaneously for each sample. The information about the phase transitions and transformations were determined by the inflection points (peaks) in DTA diagrams [11, 52] (dash-point curve in Figure 7).

From the thermal analysis diagrams (Figure 7) different temperature ranges can be defined. The first observed effect is the evaporation of moisture and the water in capillary pores in the range from 20 to $250^{\circ} \mathrm{C}$ ( $4.5 \%$ wt of mass loss) [36, 53, 54]. The second, in the range of 250 and $400{ }^{\circ} \mathrm{C}$, dehydration of C-S-H gel is observed, with a total loss mass of $2.5 \%$ wt [52, 54]. 


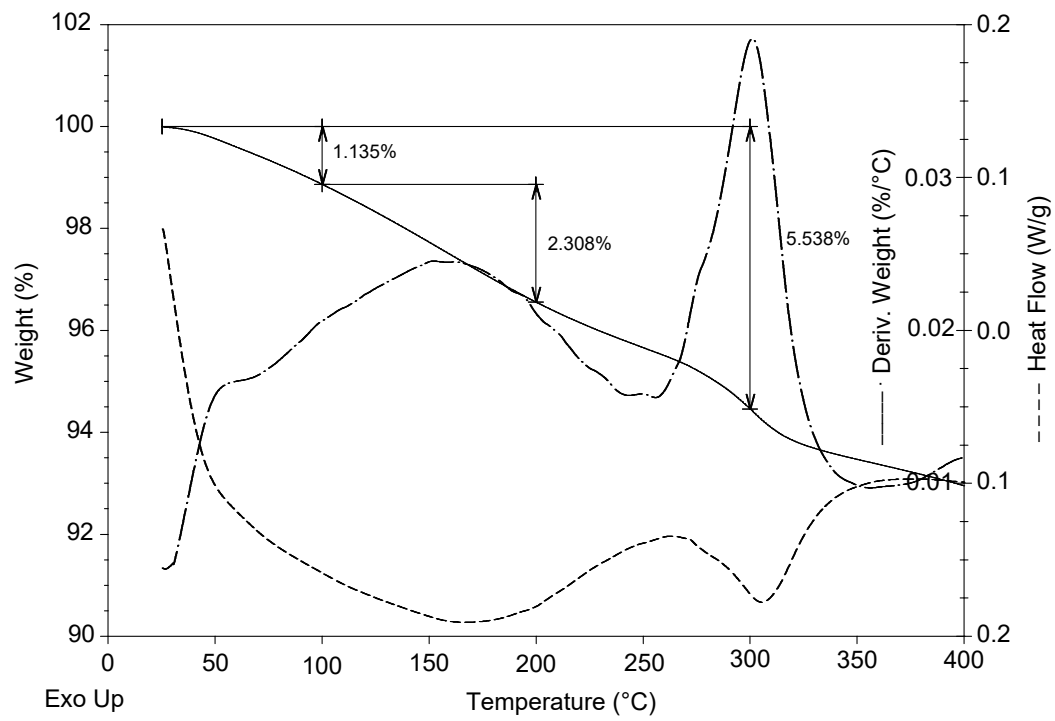

Figure 7: Plots of the TG, DTA and DSC curves of UHPC sample from room temperature to $400{ }^{\circ} \mathrm{C}$

\subsection{Analyses of the porosity by X-ray CT images}

The interpretation of X-ray CT data was performed using Avizo software, which is specialized in X-ray CT treatments. The porosity, $\phi$, their average and maximum equivalent diameter, $d_{e q}^{a v}$ and $d_{e q}^{\max }$, and the average sphericity $\Psi^{a v}$ are shown in Table 2 at room temperature and $300{ }^{\circ} \mathrm{C}$ for each mixture, UHPC and UHPFRC. The porosity parameters in Table 2 have been determined as display below:

$$
\begin{gathered}
\phi=\frac{V_{\text {pores }}}{V_{\text {sample }}-V_{\text {fibers }}}, \\
d_{\text {eq }}=\sqrt[3]{\frac{6 V_{\text {pore }}}{\pi}}, \\
\Psi=\frac{\pi^{1 / 3} 6 V_{\text {pore }}^{2 / 3}}{A_{\text {pore }}},
\end{gathered}
$$

where $V_{\text {pore }}$ is the volume of pore analyzed, $V_{\text {sample }}$ is the total volume of sample, $V_{\text {fibers }}$ is the volume occupied by fibers within the sample analyzed and $A_{\text {pore }}$ is the 
surface area of a pore.

Table 2: Porosity parameters of mixes at room temperature (RT) and $300^{\circ} \mathrm{C}$

\begin{tabular}{c|c|c}
\hline Parameters & $\mathrm{RT}$ & $300{ }^{\circ} \mathrm{C}$ \\
\hline$\phi(\%)$ for UHPC & $3.9 \pm 0.1$ & $5.0 \pm 0.3$ \\
$d_{e q}^{a v}(\mathrm{~mm})$ for UHPC & $0.29 \pm 0.03$ & $0.29 \pm 0.02$ \\
$d_{e q}^{\text {max }}(\mathrm{mm})$ for UHPC & $2.36 \pm 0.29$ & $2.40 \pm 0.27$ \\
$\Psi^{a v}$ for UHPC & $0.97 \pm 0.01$ & $0.96 \pm 0.01$ \\
\hline$\phi(\%)$ for UHPFRC & $1.9 \pm 0.1$ & $2.6 \pm 0.1$ \\
$d_{e q}^{a v}(\mathrm{~mm})$ for UHPFRC & $0.38 \pm 0.08$ & $0.27 \pm 0.01$ \\
$d_{e q}^{\text {max }}(\mathrm{mm})$ for UHPFRC & $2.67 \pm 0.50$ & $2.69 \pm 0.49$ \\
$\Psi^{a v}$ for UHPFRC & $0.92 \pm 0.02$ & $0.92 \pm 0.02$ \\
\hline
\end{tabular}

From values of the porosity and cumulative pore volume of each pore, their evolution with regard to the equivalent diameter is presented in Figure 8 At room temperature, it is observed as the addition of steel fibers (UHPFRC) significantly reduces the porosity, $\phi$ (Figure 8 a), from $3.9 \%$ to $1.9 \%$ in the concrete matrix in comparison to non-reinforced concrete (UHPC), as also can been confirmed in Table 2 results. Although some authors have obtained that the fiber addition distorts the concrete matrix and the pore volume can increases [9, 10], other authors have obtained a decrease in the pore volume for high contents of fiber as occurred to Wang et al. [55] and Ponikiewski et al. $[8]$ in their porosity studies of concrete mixes with different fiber volume content. 


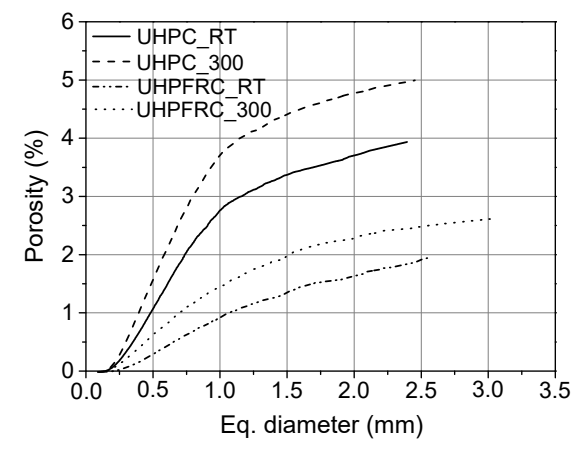

(a)

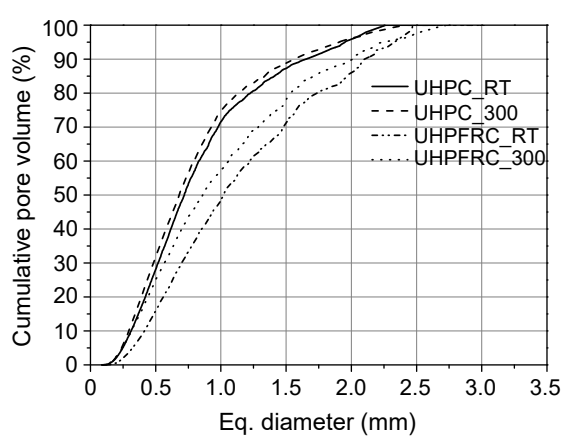

(b)

Figure 8: Equivalent diameter distribution: (a) porosity and (b) cumulative pore volume

The heating of the material to $300{ }^{\circ} \mathrm{C}$ increases its porosity (Figure 8 a), from $3.9 \%$ to $5.0 \%$ for UHPC and from $1.9 \%$ to $2.6 \%$ for UHPFRC (Table2), which implies a thermal damage generated within the material. The heating of UHPC samples causes high internal pressure as a result of two processes: the evaporation of free water, between 20 and $250{ }^{\circ} \mathrm{C}$ [54], and dehydration of C-S-H gel [53, 54], between 250 and $400{ }^{\circ} \mathrm{C}$, as additionally was confirmed for these mixes from the thermogravimetric analyses (Figure 77, as described in the previous subsection. These effects in conjunction with the lower porosity of the matrix in UHPC with respect to ordinary concrete [1, 56], leads to high internal stresses that infer into the propagation of thermal damage. If the damage is significantly high, might lead to an explosive spalling [11, 13, 14, 15]. Figure 8]b reveals that the UHPC shows an almost identical pore-size distribution curve at RT and $300{ }^{\circ} \mathrm{C}$. However, the UHPFRC shows a wider difference on the pore-size distribution by thermal effect that infer no homogenization with regard to damage propagation.

\subsubsection{Diagrams of equivalent diameter}

Using the geometrical data of each pore, the diagrams of equivalent diameter at RT and $300{ }^{\circ} \mathrm{C}$ have been performed for each mixture, UHPC in Figure 9 and UHPFRC in Figure 10, from the division of the entire range of values into intervals. These diagrams (Figure 9 or Figure 10] represent pore density, which is defined as the number of pores per cubic millimeter. 
In Figure 9, it is observed that the maximum concentration of pores is in the interval range $0.15-0.20 \mathrm{~mm}$ of the equivalent diameter and more than $50 \%$ of pore density is between $0.10-0.25 \mathrm{~mm}$. That implies a high packing density of matrix in a UHPC as was expected [57]. The amount of pores with an equivalent diameter higher than $0.6 \mathrm{~mm}$ is almost nonexistent. When the UHPC is heated at $300{ }^{\circ} \mathrm{C}$, the generated thermal damage in the matrix of concrete clearly increased pore density in every pore-diameter interval. It is worth noting that as the damage affected more severely to the lowest equivalent diameter and the interval range most influenced was the 0.15 $0.20 \mathrm{~mm}$ range which is the interval of the highest pore density at RT.

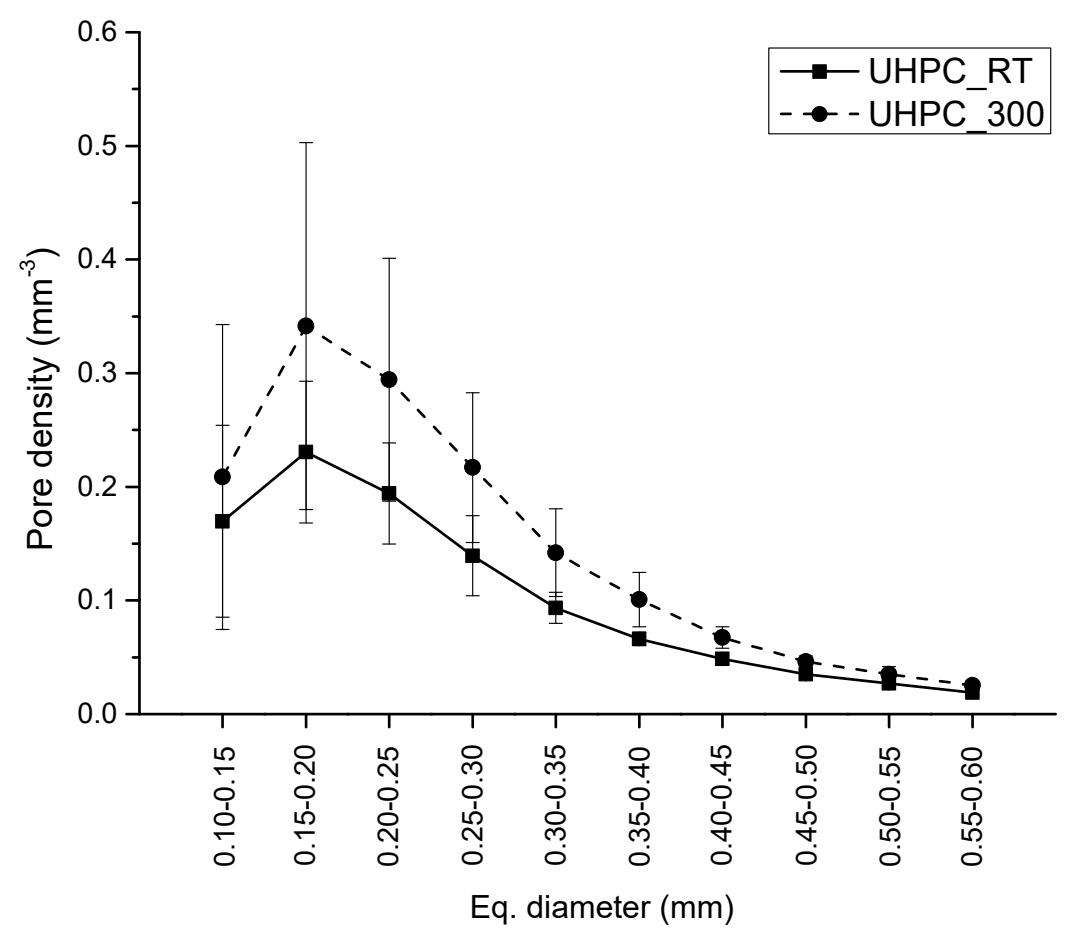

Figure 9: Equivalent diameter distribution of UHPC at RT and $300^{\circ} \mathrm{C}$ represented by pore density

Regarding the UHPFRC equivalent diameter results (Figure 10), it is shown a decrease of porosity at RT, always below the UHPC values (Figure 9), so that the ad265 dition of steel fibers decrease the porosity of matrix, as demonstrated in Table 2 and Figure 8 The interval range of equivalent diameter with higher pore density is between 
$0.15-0.30 \mathrm{~mm}$ and the higher value 0.04 pores $/ \mathrm{mm}^{3}$. The pore density diagram is remarkably flat which infers a significant low porosity and a uniform distribution of pore size in comparison with UHPC (Figure 9). When the UHPFRC concrete is heated to $300{ }^{\circ} \mathrm{C}$ (Figure 10), it is observed as the thermal damage modifies the pore distribution in the concrete matrix due to an increase of pore density specially in the interval range $0.10-0.25 \mathrm{~mm}$, as shown in Figure 10

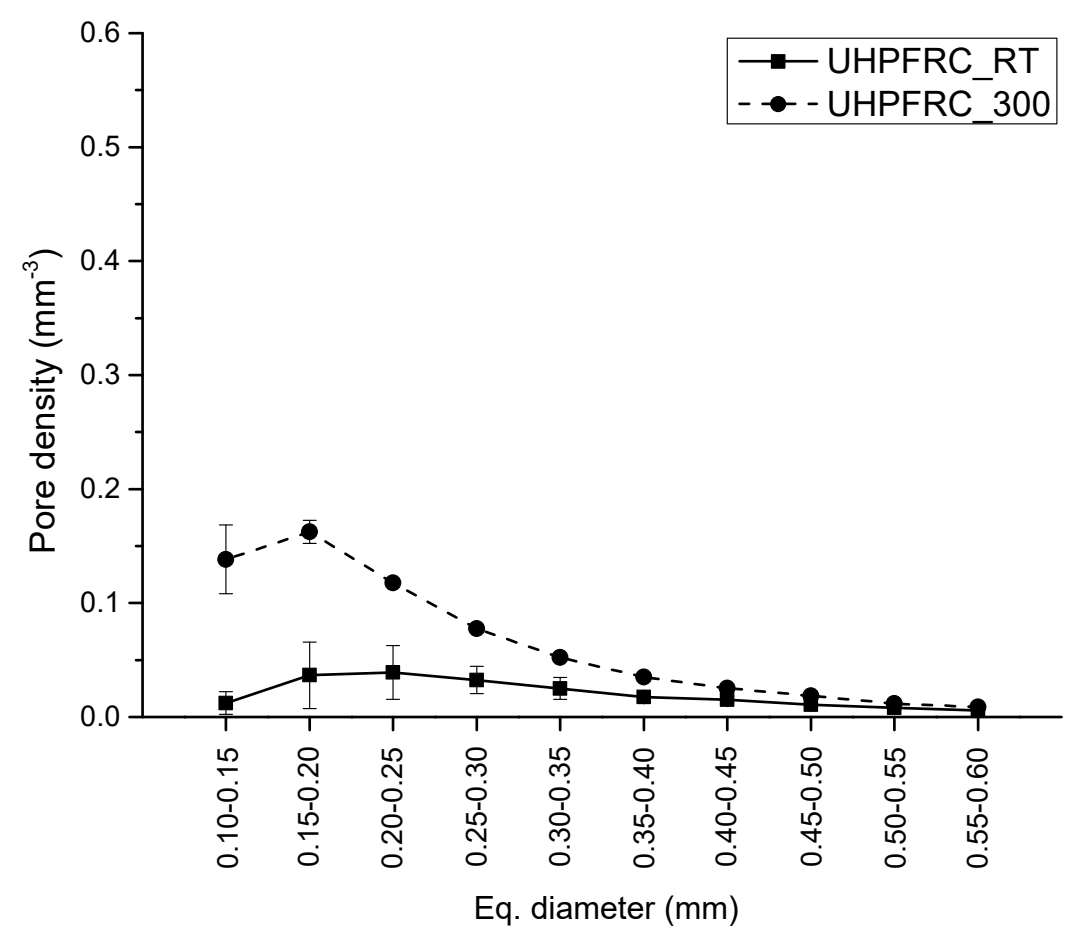

Figure 10: Equivalent diameter distribution of UHPFRC at RT and $300^{\circ} \mathrm{C}$

The maximum interval range of pore density is $0.15-0.20 \mathrm{~mm}$, as occurred in UHPC at any temperature although the pore density value is lower than those cases $(0.16$ pores $\left./ \mathrm{mm}^{3}\right)$.

\subsubsection{Diagrams of pore volume}

Diagrams of pore volume for each mixture, UHPC in Figure 11 and UHPFRC in Figure 12, are represented from the division of the entire range of values into intervals. 
The $\mathrm{x}$-axis represents the range of pore volume $\left(\right.$ in $\mathrm{mm}^{3}$ ) and the $\mathrm{y}$-axis displays pore density.

Regarding the UHPC, the Figure 11 shows that the most significant concentration of pores is contained in the $0.001-0.002 \mathrm{~mm}^{3}$ interval range with pore density value of 0.14 pores $/ \mathrm{mm}^{3}$. There is a higher pore concentration (more than 50\%) in the range below $0.009 \mathrm{~mm}^{3}$ that confirms the low porosity of matrix expected for this type of concrete. When the temperature in the UHPC reaches $300{ }^{\circ} \mathrm{C}$, the thermal damage in the matrix is derived into a higher pore density in the interval range of pore volume below $0.017 \mathrm{~mm}^{3}$. It is interesting remark as the biggest pores are not influences by the thermal damage. The maximum pore density occurs in the same maximum interval range (0.001-0.002 $\left.\mathrm{mm}^{3}\right)$, yet the value rises into 0.18 pores $/ \mathrm{mm}^{3}$.

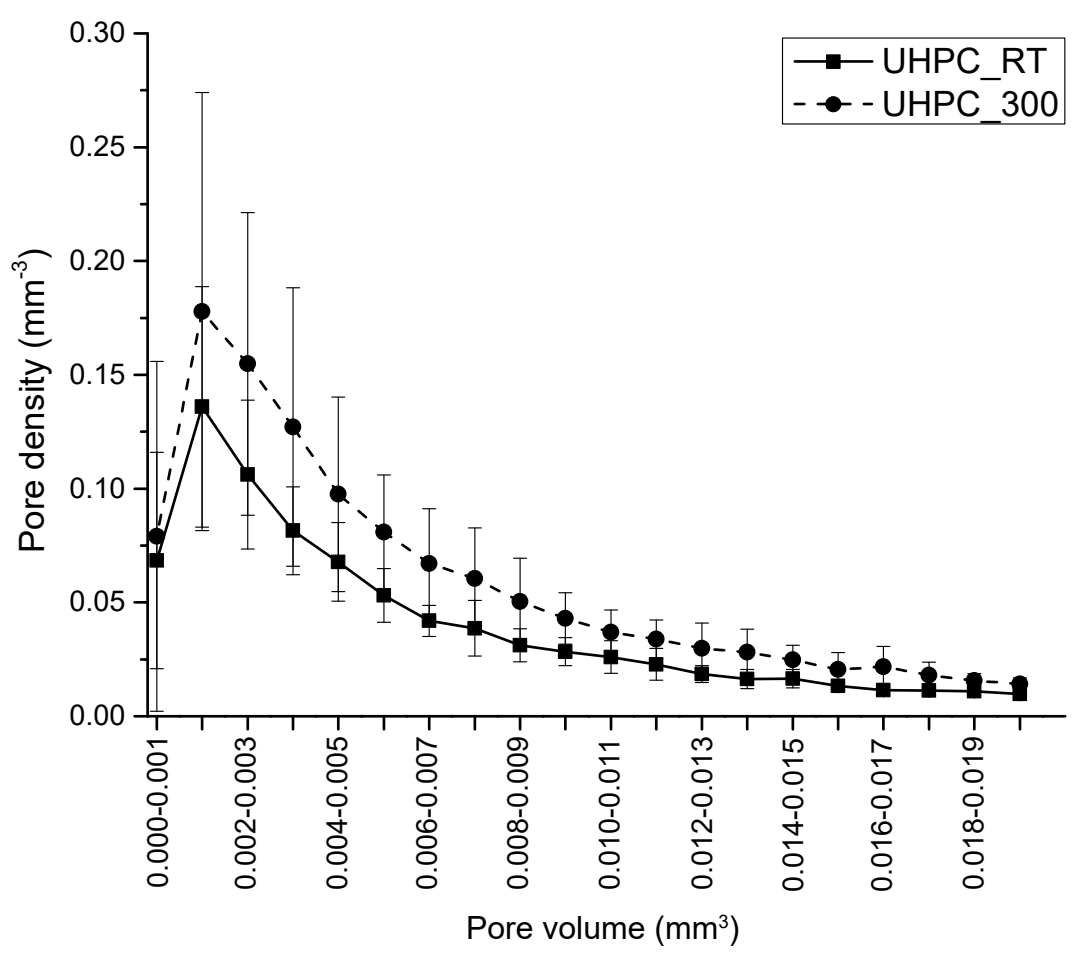

Figure 11: Pore volume distribution of UHPC at RT and $300^{\circ} \mathrm{C}$ : (a) pore density and (b) percentage of pores

In the UHPFRC at RT (Figure 12), it is observed a significant decrease of pore density in all interval range leading to a greatly low porosity due to the addition of 
steel fibers. The maximum pore density is between $0.001-0.002 \mathrm{~mm}^{3}$ with a value of 0.018 pores $/ \mathrm{mm}^{3}$. The effects of thermal damage at $300{ }^{\circ} \mathrm{C}$ in the pore density diagram (Figure 12) showed a sizeable increment in the pore volume range below $0.005 \mathrm{~mm}^{3}$ (50\% of pore volume) but not a significant influence for higher pore volume. The maximum pore density is generated in the interval range $0.001-0.002 \mathrm{~mm}^{3}$. This is in accordance with that results observed for equivalent diameter diagrams.

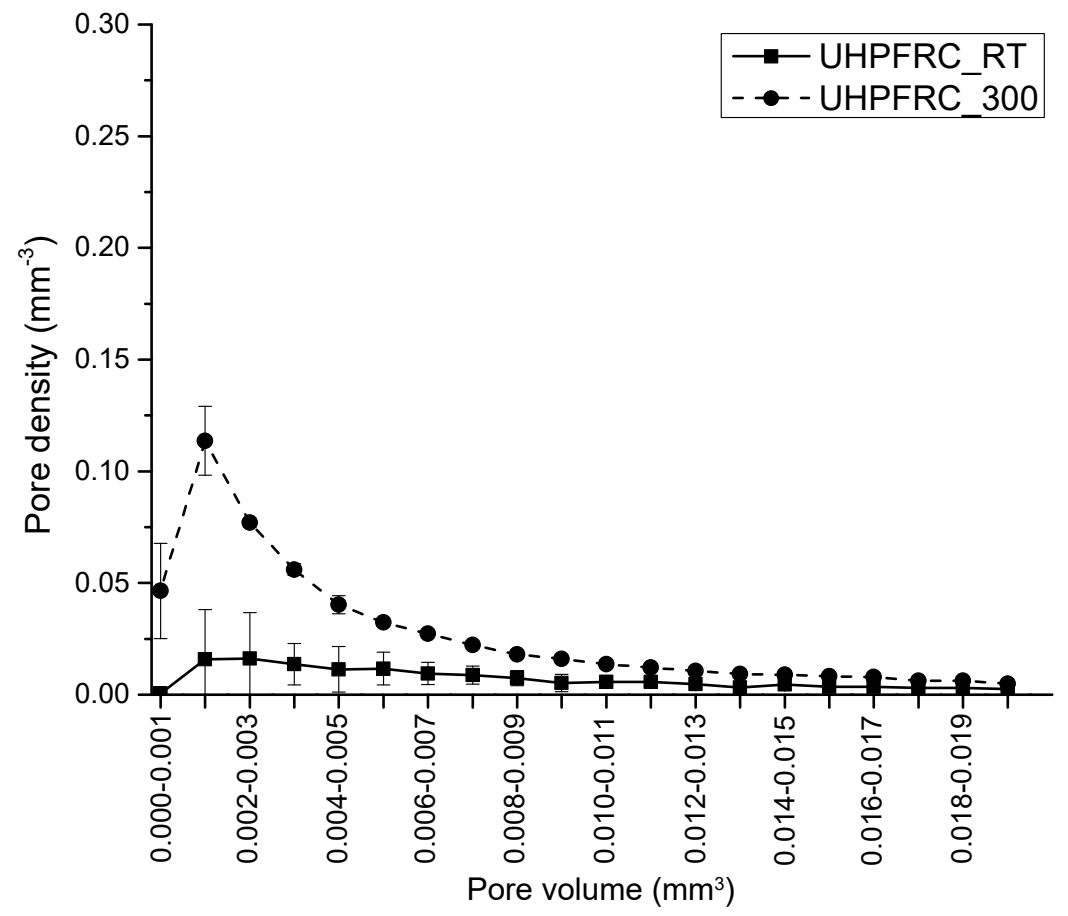

Figure 12: Pore volume distribution of UHPFRC at RT and $300{ }^{\circ} \mathrm{C}$ : (a) pore density and (b) percentage of pores

Table 3 summaries pore density (in pores $/ \mathrm{cm}^{3}$ ) and outlines the pore volume intervals higher than $0.1 \mathrm{~mm}^{3}$, in which the amount of pores are less numerous and as a consequence they were not included in Figure 11 and Figure 12. Regarding the thermal effect in the UHPC in comparison to the UHPFRC, it is shown as the porosity with pore volume higher than $0.5 \mathrm{~mm}^{3}$ is not affected, as it is inferred of the invariability of pore density for any type of mixture (UHPC and UHPFRC) and temperature (RT and 
$300{ }^{\circ} \mathrm{C}$ ). Nevertheless, pore density lower than $0.5 \mathrm{~mm}^{3}$ rises due to the thermal dam-

Table 3: Pore density results organized by pore volume ranges at RT and $300{ }^{\circ} \mathrm{C}$

\begin{tabular}{c|c|c|c|c}
\hline & \multicolumn{4}{|c}{ Pore density (pores $\left./ \mathrm{cm}^{3}\right)$} \\
\hline & $>1 \mathrm{~mm}^{3}$ & $1-0.5 \mathrm{~mm}^{3}$ & $0.5-0.1 \mathrm{~mm}^{3}$ & $<0.1 \mathrm{~mm}^{3}$ \\
\hline UHPC RT & $3 \pm 1$ & $6 \pm 2$ & $67 \pm 13$ & $1020 \pm 254$ \\
\hline UHPC 300 ${ }^{\circ} \mathrm{C}$ & $3 \pm 1$ & $6 \pm 3$ & $90 \pm 7$ & $1680 \pm 625$ \\
\hline \hline UHPFRC RT & $3 \pm 1$ & $4 \pm 1$ & $26 \pm 7$ & $245 \pm 115$ \\
\hline UHPFRC 300 ${ }^{\circ} \mathrm{C}$ & $3 \pm 0$ & $4 \pm 0$ & $31 \pm 3$ & $644 \pm 40$ \\
\hline
\end{tabular}

From the sphericity results for each pore, the average value is shown in Table 2 for each mixture and temperature. As observed, the thermal effect has not significant influence on the sphericity of both mixes (UHPC or UHPFRC) because only the smallest pore-size, whose $V_{\text {pore }} / A_{\text {pore }}$ ratio is higher, are deteriorated by thermal damage. Thus, the sphericity does not suffer significant variations in their values, as can be seen in Table 2. Regarding the UHPC in comparison with UHPFRC, it is observed as the fiber addition infers a slight reduction on the sphericity due to air bubbles generated in the casting of fresh concrete that are positioned around steel fiber and it produces the pore structure deformation [9, 10], as can be observed in Figure 13 . 


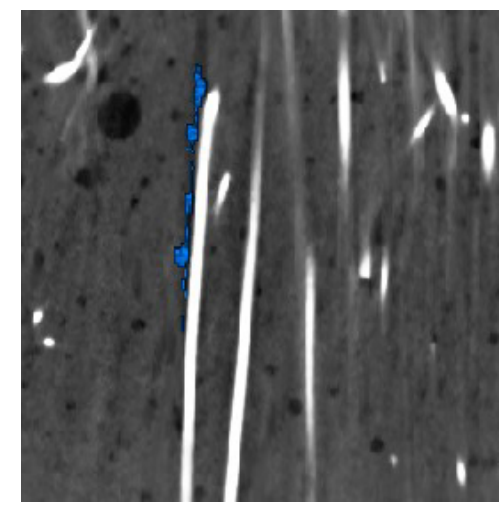

Figure 13: Pores around fibers with sphericity lower than 0.4

At $300{ }^{\circ} \mathrm{C}$, it is concluded that small pores are the most numerous in concrete, both in equivalent diameter and in volume in any type of concrete, UHPC or UHPFRC. The internal pressure produced by the temperature exposure affects more strongly to the smallest pores but the damage propagation in the concrete matrix by heating depends on the mix, UHPC or UHPFRC. In the UHPC, the absent of steel fibers, which act like barriers avoiding the damage propagation, generates higher total porosity and a more uniformly pore-size distribution in the concrete matrix. In the UHPFRC, the total porosity is reduced by the presence of an elevated amount of fibers, yet the pore-size is slightly higher due to the air bubbles concentration around fibers, as can be seen in $d_{e q}^{a v}$ and $d_{e q}^{\max }$ at RT (Table 2). Furthermore, the thermal damage propagation leads to a clear concentration of porosity in the smallest pore-size range due to the bridge effect of fibers that prevent damage propagation. This is in accordance with $d_{e q}^{a v}$ in Table 2 whereby this is practically constant for UHPC and lower for UHPFRC at $300^{\circ} \mathrm{C}$.

\subsection{Mechanical and fracture properties}

In this section, the mechanical and fracture properties of UHPC and UHPFRC are shown. All results correspond to the average of four specimens tested for each mixture and temperature with indication of the standard deviation. 


\subsubsection{Mechanical properties}

From the mechanical property tests, the compressive strength, $f_{c}$, and Young's modulus, $E_{c}$, of each mix and temperature are shown in Table 4. Comparing the UHPC and the UHPFRC at RT, the compressive strength in the UHPFRC is higher due to the presence of fibers reducing the total porosity of the material, as shown in the porosity values in Table 2 and the bridge effect of fibers which difficult the crack propagation. The Young's modulus slightly increased, showing that the fiber reinforcement does not provide remarkable enhancement, as obtained by other authors [60]. Regarding the UHPC and UHPFRC at $300{ }^{\circ} \mathrm{C}$, both materials led to a lower compressive strength and Young's modulus due to the higher porosity generated by thermal damage within the concrete matrix. The main difference was that the decreasing in UHPFRC was significantly higher than UHPC, in $15 \%$ and $8 \%$ respectively because the pore density change is higher in UHPFRC, as shown in Figure 12

Table 4: Mechanical properties of UHPC and UHPFRC at room temperature and $300{ }^{\circ} \mathrm{C}$

\begin{tabular}{c|c|c|c|c}
\hline & \multicolumn{2}{|c|}{ room temperature } & \multicolumn{2}{c}{$30{ }^{\circ} \mathrm{C}$} \\
\hline & UHPC & UHPFRC & UHPC & UHPFRC \\
\hline$f_{c}(\mathrm{MPa})$ & $124.6 \pm 7.7 \%$ & $147.4 \pm 6.4 \%$ & $114.1 \pm 19.0 \%$ & $125.5 \pm 13.9 \%$ \\
$E_{c}(\mathrm{GPa})^{*}$ & $47.7 \pm 3.2 \%$ & $49.2 \pm 2.9 \%$ & $28.2 \pm 5.4 \%$ & $30.4 \pm 4.2 \%$ \\
\hline
\end{tabular}

* Measured on cooled specimens (residual property)

\subsubsection{Fracture properties}

The fracture properties of UHPC and UHPFRC at RT and $300{ }^{\circ} \mathrm{C}$ are shown in Table 5. The tensile strength, $f_{t}$, was determined from the bilinear softening diagram parameters in the UHPFRC and from the splitting test in the UHPC because is not possible to obtain a softening behavior at $300{ }^{\circ} \mathrm{C}$. To identify the parameters of the bilinear tension softening diagrams of the mixes an inverse procedure was used based on the non-linear hinge concept [44, 45, 46]. The size-independent fracture energy was determined according to the work-of-fracture method of RILEM with the corrections proposed by Guinea et al. [41, 42, 43]. The fracture energy and the characteristic 
length are defined as follows:

$$
\begin{gathered}
G_{F}=\frac{W_{F . M}+W_{F . N M}}{A_{l i g}}, \\
l_{c h}=\frac{G_{F} E_{c}}{f_{t}^{2}},
\end{gathered}
$$
displacement curve), $W_{F . N M}$ is the non-measured work-of-fracture and $A_{l i g}$ is the ligament area.

Regarding the room temperature tests, as the tensile strength results, $f_{t}$, of UHPC were determined by splitting tensile tests and of UHPFRC by bilinear inverse analyses.

This leads to cannot compare the results of UHPC with UHPFRC although it is possible to do a qualitative comparison. In both mixes, it is showed a significant increase of tensile strength due to the fiber-reinforcement, as expected. The steel fibers have a bridge effect on the crack front that avoid any eventual micro-cracking. The fracture energy, $G_{F}$, and characteristic length, $l_{c h}$, are extremely higher in UHPFRC than UHPC due to the presence of fibers. In the UHPC and UHPFRC at $300{ }^{\circ} \mathrm{C}$, the tensile strength greatly decreased due to the same reasons that the thermal damage affected the compressive strength. The fracture energy was reduced to $40 \%$ on UHPFRC. For UHPC it could not be determined because the CMOD and LVDT transducers does not support that temperature. The characteristic length was strongly increased up to $64 \%$ 
Table 5: Fracture properties of UHPC and UHPFRC at room temperature and $300{ }^{\circ} \mathrm{C}$

\begin{tabular}{c|c|c|c|c}
\hline & \multicolumn{2}{|c|}{ room temperature } & \multicolumn{2}{c}{$300^{\circ} \mathrm{C}$} \\
\hline & UHPC & UHPFRC & UHPC & UHPFRC \\
\hline$f_{t}(\mathrm{MPa})$ & $5.9 \pm 16.3 \%$ & $16.3 \pm 25.0 \%$ & $3.7^{*} \pm 7.4 \%$ & $9.4 \pm 19.6 \%$ \\
$G_{F}(\mathrm{~N} / \mathrm{m})$ & $63.36 \pm 5.3 \%$ & $54973 \pm 8.1 \%$ & - & $26919 \pm 18.6 \%$ \\
$l_{c h}(\mathrm{~mm})$ & - & $3315 \pm 8.1 \%$ & - & $9339 \pm 18.6 \%$ \\
\hline
\end{tabular}

* This property was determined by splitting tensile tests on cooled cylindrical specimens.

\subsubsection{Bilinear softening diagrams}

Figure 14 shows the result of the non-linear hinge model method over the loaddeflection curves. The experimental load-deflection curve (continuous line) is the average of four tests. The hinge model method was applied on the mean load-deflection curves of UHPFRC at RT (Figure 14 a) and $300{ }^{\circ} \mathrm{C}$ (Figure 14 b). As observed, the maximum bearing capacity and the work-of-fracture corresponding to the total area below the load-deflection curve decreases caused by the thermal damage in accordance with the fracture energy results shown in Table 5

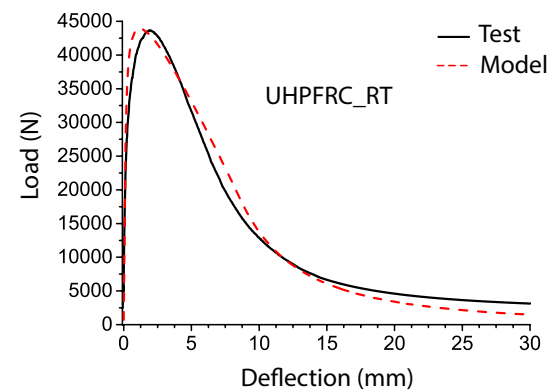

(a)

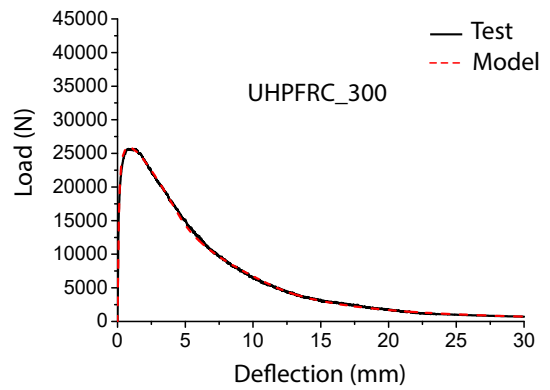

(b)

Figure 14: Average experimental load-deflection curves and fitted hinge model (a) at room temperature and (b) at $300^{\circ} \mathrm{C}$

The bilinear tension softening diagrams are shown in Figure 15 . The area below the bilinear diagram decreased coherently with the fracture energy results shown in Table 4 
and the load-deflection curves (Figure 14). Table 6 shows the values of the parameters of the bilinear tension softening diagram corresponding to Figure 15 .

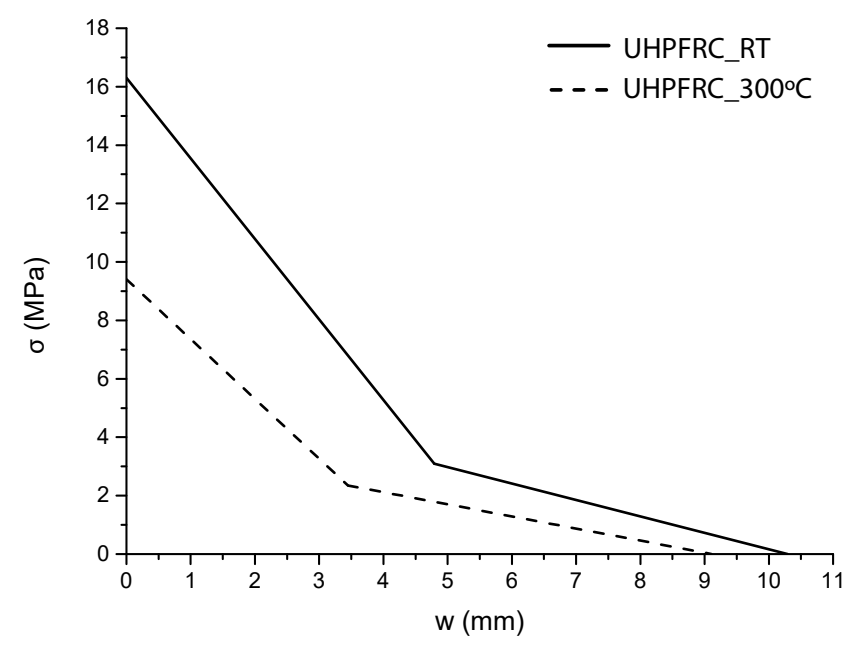

Figure 15: The average bilinear stress-crack opening width diagram for UHPFRC at room temperature and $300{ }^{\circ} \mathrm{C}$

Table 6: Parameters of the bilinear softening diagram corresponding to the size-independent specific fracture energy at room temperature and $300{ }^{\circ} \mathrm{C}$

\begin{tabular}{c|c|c|c|c|c}
\hline UHPFC & $a_{1}\left(\mathrm{~mm}^{-} 1\right)$ & $a_{2}\left(\mathrm{~mm}^{-} 1\right)$ & $\mathrm{w}_{1}(\mathrm{~mm})$ & $\mathrm{w}_{c}(\mathrm{~mm})$ & $\sigma_{1}(\mathrm{MPa})$ \\
\hline room temperature & 2.755 & 0.563 & 4.79 & 10.29 & 3.10 \\
$300^{\circ} \mathrm{C}$ & 2.043 & 0.395 & 3.45 & 9.11 & 2.35 \\
\hline
\end{tabular}

Additionally, Table 7 shows the values of the toughness indices according to the ASTM standard [61] for UHPFRC at RT and $300^{\circ} \mathrm{C}$, which were determined from the experimental average load-deflection curves in Figure 14. As it is shown, the thermal damage at $300{ }^{\circ} \mathrm{C}$ rises the toughness of concrete in any interval $\left(I_{5}, I_{10}\right.$ and $\left.I_{30}\right)$ as shown in Table 7 On the other hand, as all specimens had the same size, a ductility analyses can be performed from the characteristic length values in Table 5 [62]. The ductility on the UHPFRC at $300{ }^{\circ} \mathrm{C}$ increased (Table 5) due to the greater quantity of 
pores in its matrix (Table 2), as expected. The evolution of toughness and ductility values shown to be in accordance.

Table 7: Toughness indices of UHPFC specimens at room temperature and $300{ }^{\circ} \mathrm{C}$

\begin{tabular}{c|c|c|c}
\hline UHPFC & $\mathrm{I}_{5}$ & $\mathrm{I}_{10}$ & $\mathrm{I}_{30}$ \\
\hline room temperature & 4.08 & 8.98 & 29.06 \\
$300^{\circ} \mathrm{C}$ & 5.46 & 11.93 & 39.86 \\
\hline
\end{tabular}

\subsection{Effects of matrix microstructure on mechanical and fracture behavior}

In this section, a more detailed discussion regarding the influence of the observed changes in the microstructure of the matrix (porosity) on the mechanical and fracture properties of concrete.

\subsubsection{Effect on compression strength and Young's modulus}

The dependence of the compressive strength of concrete with the porosity of its matrix has been widely studied by several authors in the past [63, 64, 65]. Obviously, an increase of the porosity leads to a reduction of compressive strength [63] and the studies have been mainly focused on the determination of the relationship between compressive strength and porosity (or internal structure) of the matrix. Thus, the increase of compressive strength obtained in this work for the UHPFRC, at room temperature, with respect to the non-reinforced mix is due to the crack bridging effect of fibers and the reduction of porosity in the matrix originated by the fiber's addition. At $300{ }^{\circ} \mathrm{C}$ the increase of porosity, originated by the steam pressure generated in the heated matrix, leads to a decrease in compressive strength (Table 4). The heating causes an increase in porosity of $37 \%$, which produces a reduction in the compressive strength of $15 \%$.

With regard to the Young's modulus of the studied concretes, the addition of steel fibers did not show a clear influence on this parameter (Table 4), as had been obtained by other authors [60]. However, the damage of the microstructure of the matrix, caused by the increase in temperature, clearly reduce this property. Some authors [66] obtained that this parameter is influenced fundamentally by the existence of a large number of 
pores with sizes in the order of nanometers, rather than by the existence of a smaller number of pores with sizes in the order of millimeters. As can be observed from results (Table 3), the addition of steel fibers especially modifies the pore structure of the matrix at the microscale so it is not observed any remarkable improvement of the Young's modulus for the fiber-reinforced mix with respect to the non-reinforced one (Table 4). Nonetheless, the thermal damage generated by the vapour pressure affect to the smallest pores at the nanoscale, reducing significantly the value of the Young's modulus (41\% and $38 \%$ for the UHPC and UHPFRC mixes respectively).

\subsubsection{Effect of porosity on fracture behavior}

The fracture of concrete requires the development of the well-known Fracture Process Zone (FPZ) [67], which include the processes of micro-cracking, coalescence, crack branching and frictional interlocking inferred through the weak interfacial transition zone (ITZ) between aggregates and the cement paste [68]. According to the fictitious crack model of Hillerborg [69], cohesive normal stresses are developed within the FPZ ahead of a pre-existing crack, with a value equal to the tensile strength of concrete at the crack tip, followed by a descending part (softening) until the stresses reach zero at the end of the FPZ. The distribution of these cohesive stresses is usually modeled by a bilinear softening diagram [70] in which the normal stress, $\sigma$, is a function of the crack opening width, w, in the FPZ (Figure 2). The first linear branch of the softening diagram is mainly related to the micro-cracking, while the second linear branch is a result of the frictional aggregate interlock [71].

In case of the concrete mixes studied in this work, the mechanisms involve in their fracture behavior are substantially different than those of normal plain concrete for two main reasons: the absence of coarse aggregate and the presence of steel fibers in the reinforced mixes. When steel fibers are added to the concrete matrix they produced a remarkable increase of its fracture properties (fracture energy and tensile strength) mainly due to the crack bridging effect of fibers [72], which greatly increases the energy absorption capacity of the fiber-reinforced concrete. Cohesive models are also applicable for the study of the fracture behavior of this type of concrete [73] when a pre-existing crack (or notch) exists. Some authors have proposed bi-linear [74, 75] tri- 
linear [73, 76] and polylinear [34] tension softening diagrams for the FPZ ahead of the crack tip in fiber-reinforced concrete.

In this work, a highly respectable agreement has been obtained between the experimental $P-\delta$ curves and the fitted ones by using the non-linear hinge model with bi-linear cohesive laws, as shown in Figure 14. The entire $\sigma-\mathrm{w}$ diagram is influenced by the presence of fibers but the initial linear branch is more related with the internal microstructure of the matrix [71] and the toughening and bridging effects of fibers [77], whereas the second linear branch is mainly governed by the pull out of fibers [73]. As can be observed in Figure 15 , the initial fracture energy $\left(G_{f}\right)$ for the analyzed UHPFRC represents a high value with respect to total energy $\left(G_{F}\right)$, essentially motivated by its dense microstructure as well as by the reinforcement of the matrix that the fibers provide. The values of $G_{f}=1 / 2 f_{t} w_{1}$ (see Figure 2) obtained at room temperature and $300^{\circ} \mathrm{C}$ are 48248 and $22043 \mathrm{~N} / \mathrm{m}$, respectively.

As has been described beforehand, heating up to $300{ }^{\circ} \mathrm{C}$ generates a high steam pressure in the concrete matrix which infers internal damage and increases the total porosity (Table 2). The most affected pores were those with a volume lower than $0.009 \mathrm{~mm}^{3}$, as observed in Figure 12 The increase in temperature generates a deterioration of the microstructure of the matrix, mainly increasing the small-size pores and subsequently, causing greater initial micro-cracking. The effects of this initial deterioration are felt in the lowest values of the mechanical properties (Table 4), as well as of the fracture parameters (fracture energy and bi-linear softening diagrams) obtained for the hot concrete (Tables 5 and 6 ).

The obtained value of the specific fracture energy was lower at $300{ }^{\circ} \mathrm{C}$ than at room temperature, due to the deterioration experienced by the matrix. This effect was also evidenced by the higher value of the characteristic length obtained at $300{ }^{\circ} \mathrm{C}$ (Table 5) and originated by the weakening of the material [62].

With regard to the bi-linear cohesive laws, it is observed that at $300{ }^{\circ} \mathrm{C}$ the slope of the initial linear branch, $a_{1}$, and the area under it , $G_{f}$, decreases with respect to the values obtained at RT, as a consequence of the increase in the porosity of the matrix and its lower resistance to crack propagation. Likewise, the value of the slope of the second linear branch, $a_{2}$, also decreases with temperature due to the deterioration of the 
internal structure of the matrix as well as the effect of concentration of small-size pores

\section{Conclusions}

In this work, the results of the thermogravimetric analyses and X-ray computed tomography techniques have been compared in order to find a direct relationship between phase changes and pore structure in the concrete matrix due to temperature exposure. with the pore structure deterioration due to the thermal damage. This issue has not been dealt with up to the present using UHPFRC and by using the X-ray CT technique. From results the following conclusions can be drawn:

- The reduction of the compressive, tensile strength and fracture energy by thermal damage is more abrupt, in relative terms, in UHPFRC due to its low initial porosity at room temperature, determined by X-ray CT scan, in comparison with UHPC.

- The internal stresses generated by thermal gradient, evaporation of moisture and dehydration process only affected to those pores smaller than $0.5 \mathrm{~mm}^{3}$ in both mixes. Nevertheless, the thermal damage within the reference UHPC matrix was propagated freely and predominantly affected to wider pore-size (below $0.04 \mathrm{~mm}^{3}$ ) than in UHPFRC matrix (below $0.01 \mathrm{~mm}^{3}$ ) where the steel fibers formed barriers to avoid the free propagation of the thermal damage. 
- The addition of steel fibers decreased the initial porosity at room temperature, improving the mechanical and fracture properties, though these deformed the porosity shown by the lower average sphericity. The lower porosity of UHPFRC leads to a more significant loss of strength by thermal damage since the internal pressure does not have any means of evacuation.

- The presence of steel fibers infers a slightly higher average pore diameter due to the known process that air bubbles in fresh concrete are preferentially positioned around fibers, which is duly confirmed with this work.

- In relative terms, the temperature effect at $300{ }^{\circ} \mathrm{C}$ damaged more significantly to UHPFRC but the mechanical properties and especially the fracture properties were still higher than UHPC because the total porosity was lower and especially affected to the smallest pore-size.

- The increase of porosity caused by the thermal damage improved the toughness and ductility of UHPFRC since the fibers, with high toughness and ductility, work more actively conducting to a higher deformation capacity.

\section{Acknowledgements}

Authors would like to acknowledge the financial support from the Ministry of Finance and Competitiveness (Ministerio de Economía y Competitividad) through the provision of funds for the project BIA2016-75431-R and the Czech Academy of Sciences by means of the project No. 16-18702S.

\section{References}

[1] Q. Song, R. Yu, X. Wang, S. Rao, Z. Shui, A novel self-compacting ultra-high performance fibre reinforced concrete (SCUHPFRC) derived from compounded 
high-active powders, Construction and Building Materials 158 (2018) 883-893. doi:10.1016/j.conbuildmat.2017.10.059.

[6] D.-Y. Yoo, S.-T. Kang, Y.-S. Yoon, Effect of fiber length and placement method on flexural behavior, tension-softening curve, and fiber distribution characteristics of UHPFRC, Construction and Building Materials 64 (2014) 67-81. doi:10 . $1016 / j . c o n b u i l d m a t .2014 .04 .007$.

[7] E. Poveda, G. Ruiz, H. Cifuentes, R. C. Yu, X. X. Zhang, Influence of the

[8] T. Ponikiewski, J. Katzer, M. Bugdol, M. Rudzki, Determination of 3D porosity in steel fibre reinforced SCC beams using X-ray computed tomography, 
Construction and Building Materials 68 (2014) 333-340. doi:10.1016/j. conbuildmat.2014.06.064

[9] C. Jiang, K. Fan, F. Wu, D. Chen, Experimental study on the mechanical properties and microstructure of chopped basalt fibre reinforced concrete, Materials \& Design 58 (2014) 187-193. doi:10.1016/j.matdes.2014.01.056

[11] A. H. Akca, N. Özyurt Zihnioglu, Effects of re-curing on residual mechanical properties of concrete after high temperature exposure, Construction and Building 570

[14] A. H. Akca, N. Özyurt Zihnioglu, High performance concrete under elevated

[15] P. Kalifa, F.-D. Menneteau, D. Quenard, Spalling and pore pressure in HPC at high temperatures, Cement and Concrete Research 30 (12) (2000) 1915-1927. doi:doi.org/10.1016/S0008-8846(00)00384-7.

[16] S. Bei, L. Zhixiang, Investigation on spalling resistance of ultra-high-strength 585 concrete under rapid heating and rapid cooling, Case Studies in Construction Materials 4 (2016) 146-153. doi:10.1016/j.cscm.2016.04.001. 
[17] S. Y. N. Chan, G. fei Peng, J. K. W. Chan, Comparison between high strength concrete and normal strength concrete subjected to high temperature, Materials and Structures 29 (1996) 616-619. doi:10.1007/BF 02485969

[19] D.-Y. Yoo, S.-T. Kang, Y.-S. Yoon, Enhancing the flexural performance of ultra-

[23] M. R. Khosravani, M. Silani, K. Weinberg, Fracture studies of ultra-high performance concrete using dynamic brazilian tests, Theoretical and Applied Fracture Mechanics 93 (2018) 302-310. doi:10.1016/j.tafmec.2017.10.001

[24] L. Wan-Wendner, R. Wan-Wendner, G. Cusatis, Age-dependent size effect and high-performance concrete using long steel fibers, Composite Structures 147 (2016) 220-230. doi:10.1016/j.compstruct.2016.03.032

[20] R. Yu, P. Spiesz, H. Brouwers, Mix design and properties assessment of ultrahigh performance fibre reinforced concrete (UHPFRC), Cement and Concrete Research 56 (2014) 29-39. doi : 10.1016/j.cemconres.2013.11.002.

[21] K. Wille, A. Naaman, G. Parra-Montesinos, Ultra-high performance concrete with compressive strength exceeding $150 \mathrm{MPa}$ (22 ksi): A simpler way, ACI Materials Journal 108 (1) (2011) 1-11. doi:10.14359/51664215.

[22] B. Graybeal, Compressive behavior of ultra-high-performance fiber-reinforced 口 concrete, ACI Materials Journal 104 (2) (2007) 146-152. doi:10.14359/ 18577 .

fracture characteristics of ultra-high performance concrete, Cement and Concrete Composites 85 (2018) 67-82. doi:10.1016/j.cemcincomp.2017.09. 010 
[25] R. Sovják, P. Máca, T. Imlauf, Effect of fibre length on the fracture energy of UH-

1. PFRC, Procedia Engineering 193 (2017) 74-79. doi:10.1016/j.proeng. 2017.06 .188

[26] N. Tran, T. Tran, J. Jeon, J. Park, D. Kim, Fracture energy of ultra-highperformance fiber-reinforced concrete at high strain rates, Cement and Concrete Researchdoi:10.1016/j.cemconres.2015.09.011.

[27] K. Voit, J. Kirnbauer, Tensile characteristics and fracture energy of fiber reinforced and non-reinforced ultra high performance concrete (UHPC), In-

口. ternational Journal of Fracture 188 (2014) 147-157. doi:10.1007/ s10704-014-9951-7.

[28] M. A. Vicente, D. C. González, J. Mínguez, M. A. Tarifa, G. Ruiz, R. Hindib, Influence of the pore morphology of high strength concrete on its fatigue life, International Journal of Fatigue 112 (2018) 106-116. doi:10.1016/j. ijfatigue.2018.03.006.

[29] M.-X. Xiong, J. R. Liew, Mechanical behaviour of ultra-high strength concrete at elevated temperatures and fire resistance of ultra-high strength concrete filled

a steel tubes, Materials and Design 104 (2016) 414-427. doi:10.1016/j. 630 matdes.2016.05.050

[30] F. M. Nazri, R. P. Jaya, B. H. A. Bakar, R. Ahmadi, Fire resistance of ultra-high performance fibre reinforced concrete due to heating and cooling, MATEC Web of Conferences 87.

[31] C. Kahanji, F. Ali, A. Nadjai, Explosive spalling of ultra-high performance fibre reinforced concrete beams under fire, Journal of Structural Fire Engineering 7 (4) (2017) 328-348. doi:10.1108/JSFE-12-2016-023.

[32] P. Shen, L. Lu, Y. He, M. Rao, Z. Fu, F. Wang, S. Hua, Experimental investigation on the autogenous shrinkage of steam cured ultra-high performance concrete, Construction and Building Material 162 (2018) 512-522. doi:10.1016/j. 
[33] Çaglar Yalçınkaya, H. Yazıcı, Effects of ambient temperature and relative humidity on early-age shrinkage of UHPC with high-volume mineral admixtures,

1. Construction and Building Material 144 (2017) 252-259. doi:10.1016/j. conbuildmat.2017.03.198

[36] C. Leiva, H. Cifuentes, C. Fernandez-Pereira, F. Medina, Effects of fibers and rice husk ash on properties of heated high-strength concrete, Magazine of Concrete

[38] EN-12390-3:2009, Testing hardened concrete Part 3: Compressive strength of test specimens, AENOR, 2009.

[39] EN-12390-13:2014, Testing hardened concrete Part 13:Determination of secant modulus of elasticity in compression, AENOR, 2014.

[40] RILEM-TCM-85, Determination of the fracture energy of mortar and concrete by means of three-point bend tests on notched beams, Materials and Structures 4 (18) (1985) 287-290. doi:0.1007/BF 02472918. 
[41] G. Guinea, J. Planas, M. Elices, Measurement of the fracture energy using threepoint bend tests: Part 1 - influence of experimental procedures, Materials and Structures 25 (1992) 212-218. doi:10.1007/BF02473065.

[42] J. Planas, M. Elices, G. Guinea, Measurement of the fracture energy using threepoint bend tests: Part 2 - influence of bulk energy dissipation, Materials and Structures 25 (1992) 305-312. doi:10.1007/BF 02472671 .

[43] M. Elices, G. Guinea, J. Planas, Measurement of the fracture energy using threepoint bend tests: Part 3 - influence of cutting the $\mathrm{p}-\delta$ tail, Materials and Structures 25 (1992) 327-334. doi:10.1007/BF02472591.

[44] L. Ostergaard, Early-age fracture mechanics and cracking of concrete. Experiments and modelling, PhD. Thesis. Thecnical University of Denmark, 2003.

[45] H. M. Abdalla, B. Karihaloo, A method for constructing the bilinear tension softening diagram of concrete corresponding to its true fracture energy, Magazine of Concrete Research 56 (10) (2004) 597-604. doi:10.1680/macr.2004. 56.10 .597

[46] A. R. Murthy, B. Karihaloo, N. R. Iyer, B. K. R. Prasad, Bilinear tension softening diagrams of concrete mixes corresponding to their size-independent specific fracture energy, Construction and Building Materials 47 (2013) 1160-1166. doi:10.1016/j.conbuildmat.2013.06.004.

[47] H. Cifuentes, J. D. Rios, E. J. Gomez, Effect of mix design on the sizeindependent fracture energy of normal- and high-strength self-compacting concrete, Materiales de Construccion 68 (329). doi:10.3989/mc.2018. 00717

[48] M. Alcalde, H. Cifuentes, F. Medina, Influence of the number of keys on the shear strength of post-tensioned dry joints, Materiales de Construccion 63 (310) (2013) 297-307. doi:10.3989/mc.2013.07611.

[49] B. Zhang, N. Bicanic, Fracture energy of high-performance concrete at high temperatures up to $450{ }^{\circ} \mathrm{C}$ : the effects of heating temperatures and testing condi- 
tions (hot and cold), Magazine of Concrete Research 58 (5) (2006) 277-288. doi:10.1680/macr.2006.58.5.277.

[50] A. Qsymah, R. Sharma, Z. Yang, L. Margetts, P. Mummery, Micro X-ray computed tomography image-based two-scale homogenisation of ultra high performance fibre reinforced concrete, Construction and Building Materials 130 (2017) 230-240. doi:10.1016/j.conbuildmat.2016.09.020

[51] J. P. Suuronen, A. Kallonen, M. Eik, J. Puttonen, R. Serimaa, H. Herrmann, Analysis of short fibres orientation in steel fibre-reinforced concrete (SFRC) by X-ray tomography, Journal of Materials Science 48 (3) (2013) 1358-1367. doi:10.1007/s10853-012-6882-4

[52] M. C. Alonso, L. Fernandez, Dehydration and rehydration processes of cement paste exposed to high temperature environments, Journal of Materials Science 39 (2004) 3015-3024. doi:10.1023/B: JMSC. 0000025827.65956 .18 .

[53] G. Villain, M. Thiery, G. Platret, Measurement methods of carbonation profiles in concrete: Thermogravimetry, chemical analysis and gammadensimetry, Cement and Concrete Research 37 (8) (2007) 1182-1192. doi:10.1016/j. cemconres.2007.04.015.

[54] I. G. Garcia, Carbonatación del hormigón: combinación de $\mathrm{CO}_{2}$ con las fases hidratadas del cemento y frente de cambio de pH, PhD. Thesis. School of Engineering. Universidad Politecnica de Madrid, 2011.

[55] Y. Wang, D. T. Niu, Y. Y. Miao, Influence of steel fibre on micropore structure of concrete, Materials Research Innovations 19 (2015) 1135-1139. doi:10. $1179 / 1432891714 \mathrm{Z} .0000000001264$.

[56] J. Zhao, J.-J. Zheng, G.-F. Peng, K. van Breugel, Numerical analysis of heating rate effect on spalling of high-performance concrete under high temperature 720 conditions, Construction and Building Materials 152 (2017) 456-466. doi: $10.1016 / j . c o n b u i l d m a t .2017 .07 .023$ 
[57] F. de Larrard, T. Sedran, Optimization of ultra-high-performance concrete by the use of a packing model, Cement and Concrete Research 24 (6) (1994) 997-1009. doi:0.1016/0008-8846(94)90022-1.

[58] S. Abbas, A. M. Soliman, M. L. Nehdi, Chloride ion penetration in reinforced concrete and steel fiber-reinforced concrete precast tunnel lining segments, Aci Materials Journal 111 (1-6) (2014) 1-10. doi:10.14359/51686991

[59] J. Lai, W. Sun, Dynamic behaviour and visco-elastic damage model of ultrahigh performance cementitious composite, Cement and Concrete Research 39 (1) (2009) 1044-1051. doi:10.1016/j.cemconres.2009.07.012

[60] ACI Committee 544. State-of-the-art report on fiber reinforced concrete. ACI 1R.544-96), American Concrete Institute (2001).

[61] ASTM International C 1018-97. Standard Test Method for Flexural Toughness and First-Crack Strength of Fiber-Reinforced Concrete (Using Beam With ThirdPoint Loading), ASTM Annual Book of Standards (2002).

[62] H. Cifuentes, B. Karihaloo, Determination of size-independent specific fracture energy of normal- and high-strength self-compacting concrete from wedge splitting tests, Construction and Building Materials 48 (2013) 548-553. doi: $10.1016 / j$. conbuildmat.2013.07.062.

[63] X. Chen, S. Wu, J. Zhou, Influence of porosity on compressive and tensile strength of cement mortar, Construction and Building Materials 40 (2013) 869874. doi:10.1016/j.conbuildmat.2012.11.072

[64] B.B.Dasa, Kondraivendhan, Implication of pore size distribution parameters on compressive strength, permeability and hydraulic diffusivity of concrete, Construction and Building Materials 28 (1) (2012) 382-386. doi:10.1016/j. conbuildmat.2011.08.055

[65] Erniati, M. W. Tjaronge, Zulharnah, U. R. Irfan, Porosity, pore size and compressive strength of self compacting concrete using sea water, Procedia Engineering 125 (2015) 832-837. doi:10.1016/j.proeng.2015.11.045 
[66] K. Kendall, A. J. Howard, J. D. Birchall, P. L. Pratt, B. A. Proctor, S. A. Jefferis, The relation between porosity, microstructure and strength, and the approach to advanced cement-based materials, Philosophical Transactions of the Royal Society of London. Series A, Mathematical and Physical Sciences 310 (1983) 139153. doi:10.1098/rsta.1983.0073.

[70] Z. P. Bazant, Concrete fracture models: testing and practice, Engineering Fracture

[67] J. G. M. van Mier, Fracture processes of concrete: Assesment of material parameters for fracture models, CRC Press, Boca Raton, 1996.

[68] K. L. Scrivener, A. K. Crumbie, P. Laugesen, The Interfacial Transition Zone (ITZ) Between Cement Paste and Aggregate in Concrete, Interface Science 12 (4) (2004) 411-421. doi:10.1023/B:INTS.0000042339.92990.4

[69] A. Hillerborg, M. Modéer, P.-E. Petersson, Analysis of crack formation and crack growth in concrete by means of fracture mechanics and finite elements, Cement and Concrete Research 6 (6) (1976) 773-781. doi:10.1016/ $0008-8846(76) 90007-7$.

Mechanics 69 (2002) 165-205. doi:10.1016/j.conbuildmat.2012. 11.072

[71] W. Alyhya, M. A. Dhaheer, M. Al-Rubaye, B. Karihaloo, Influence of mix composition and strength on the fracture properties of self-compacting concrete,

n. Construction and Building Materials 110 (2016) 312-322. doi:10.1016/j. $770 \quad$ conbuildmat.2016.02.037.

[72] J. A. O. Barros, J. S. Cruz, Fracture energy of steel fiber-reinforced concrete,

11. Mechanics of Composite Materials and Structures 8 (1) (2001) 29-45. doi: $10.1080 / 10759410119428$

[73] K. Park, G. H. Paulino, J. Roesler, Cohesive fracture model for functionally graded fiber reinforced concrete, Cement and Concrete Research 40 (2010) 956965. doi:10.1016/j.cemconres.2010.02.004 
[74] L. Mao, S. Barnett, D. Begg, G. Schleyer, G. Wight, Numerical simulation of ultra high performance fibre reinforced concrete panel subjected to blast load-

口 ing, Internatioonal Journal of Impact Engineering 64 (2014) 91-100. doi:

$780 \quad 10.1016 / j . i j i m p e n g .2013 .10 .003$

[75] K. Awinda, J. Chen, S. Barnett, D. Fox, Modelling behaviour of ultra high performance fibre reinforced concrete, Advnces in Applied Ceramics 113 (8) (2014) 502-508. doi:10.1179/1743676114Y.0000000201.

[76] M. Alberti, A. Enfedaque, J. Galvez, E. Reyes, Numerical modelling of the fracture of polyolefin fibre reinforced concrete by using a cohesive fracture approach,

1. Composites Part B 111 (2017) 200-210. doi:10.1016/j.compositesb. 2016.11 .052

[77] A. F. Bower, M. Ortiz, The influence of grain size on the toughness of monolithic ceramics, Journal of Engineering Materials and Technology 115 (3) (2008) 228236. doi:10.1115/1.2904212. 